\title{
La Colonia Tolstoyana: Síntesis de las tendencias artíiticas de inicios del siglo XX
}

\author{
The Tolstoyan Colony: A Synthesis of Artistic Tendencies \\ in the Early $20^{\text {th }}$ Century
}

\author{
Jaime Alberto G algan I \\ Pontificia U niversidad C atólica de Chile. Santiago, C hile \\ E-mail: jagalgan@puc.cl
}

\section{RESU MEN}

La Colonia Tolstoyana fue un proyecto liderado por Augusto $\mathrm{D}$ 'H almar entre los años 1904 y 1905. El presente artículo pretende revisar las distintas lecturas que se han realizado de dicho fenómeno, desde sus inicios hasta nuestros días, intentando mostrar que la experiencia de esta comunidad constituye - por sí misma- un cuadro de las tendencias artísticas divergentes de principios de siglo y que, dos décadas más tarde, confluirían en la contienda entre "imaginistas" y "criollistas".

Palabras claves: Colonia Tolstoyana, imaginismo, criollismo, Augusto D 'H almar, Fernando Santiván.

\section{ABST RACT}

TheTolstoy Colony was a project leaded by Augusto D 'H almar during 1904 and 1905. This article is aimed to review different readings that have been done about the phenomenon, from the beginning till today, trying to show that the experience of this community constitutes - by itself- a framework of the divergent artistic trends of the early twentieth century and that, two decades later, would converge in the dispute between "imaginistas" and "criollistas".

Keywords: The Tolstoy Colony, imaginismo, criollismo, Augusto D'H almar, Fernando Santiván.

Recibido: 04-05-2006. Aceptado: 16-06-2006. 


\section{INTRODUCCION}

A COLON IA Tolstoyana consistió en una breve experiencia artístico-comunitaria realizada entre los años 1904 y 1905, liderada por Augusto D 'H almar y seguida más de cerca por Fernando Santiván y Julio 0 rtiz de Zárate. D urante décadas, constituyó una leyenda de la vida cultural chilena, hasta que el mismo Fernando Santiván, en 1955, publicara su obra M emorias de un tolstoyano, revelando muchos datos que contribuyeron a desmitificar tanto al proyecto de la C olonia misma como a su pretendido fundador. Es así que han existido hasta ahora dos interpretaciones respecto de la tentativa tolstoyana: una lectura tradicional y confiada, por un lado, y una sospechosa, por otro.

Sin embargo, más allá de la validez o el fracaso del proyecto, lo que este artículo desea plantear es que, al interior de la Colonia Tolstoyana, cohabitaron dos tendencias estéticas dispares y que éstas fueron, en definitiva, las causantes del colapso de la misma. Por un lado, estaba la fidelidad a ultranza al proyecto social deTolstoy por parte de Santiván y 0 rtiz de Záratey, por otro, los flirteos estéticos de D ' $\mathrm{H}$ almar con los simbolistas, con M aeterlinck y Pierre Loti. D ichas preferencias configuraron, inconscientemente, un clima contradictorio que impedía que el férreo proyecto social tolstoyano se realizara en su plenitud. Junto con eso, ellas mismas permiten observar queel principal valor de la Colonia Tolstoyana está dado por el hecho de constituir, en sí misma, una síntesis de las pugnas literarias y culturales que aparecen tímidamente a inicios del siglo XX y que se expresarían más explícitamente, décadas más tarde, bajo la forma de la contienda entre criollistas e imaginistas. Es más, se afirma en este artículo que dicho conflicto no sólo se manifiesta al interior de la Colonia, sino en el mismo D 'H almar, quien, por aquel entonces, vivía su propio proceso de transición entre el relativo naturalismo de Juana Lucero y el lirismo abstracto de La lámpara en el molino.

Por otra parte, se descarta que los móviles destructivos de la Colonia Tolstoyana hayan estado en la homosexual idad de Augusto D 'H almar, según lo afirma Alone en 1962. Sin desconocer naturalmentelo valioso que ha sido para la crítica posterior el pronunciamiento que hace Alone de aquello que todos sabían pero que nadie se atrevía a comentar, parece gratuito afirmar - sin tener más datos que la apreciación subjetiva- que hayan sido las preferencias sexuales de D 'H almar las que armaron un clima "extraño" y difícil en la comunidad; al menos, resulta difícil pensar queésta haya sido una razón más determinanteque la cuestión mencionada en el párrafo anterior respecto a la confluencia de dos proyectos distintos. Aceptar que el "uranismo" d'halmariano haya causado la destrucción de la Colonia significaría reducir el problema a una cuestión sexual, descomplejizándolo y quitándole el componente cultural que, a mi juicio, es el 
que determina la suerte del pequeño grupo afincado en San Bernardo. El presupuesto sobre el cual se establece esta hipótesis es que, dada la juventud de D 'H almar, el contexto cultural chileno de inicios de siglo, los compromisos de imagen que él tenía frente a su familia y a la sociedad, impedían que sus tendencias homoeróticas se manifestaran siquiera veladamente. Además, todo parece indicar que Augusto D 'H almar necesitó de los viajes, a partir de 1907, para comenzar un proceso de relativa asunción de su problemática afectiva.

Finalmente, el artículo intenta mostrar queel período de la ColoniaTolstoyana coincide con el fin de un proceso iniciado por Augusto D 'H almar en 1900 y que va a terminar con sus viajes a partir de 1907. Dicho proceso consiste en el aislamiento en que se va sumiendo, abandonando progresivamente su labor cultural para dedicarse cada vez más a la escritura y adquirien do la forma definitiva de su soledad y las características que lo harían ser llamado posteriormente como "el hermano errante". La Colonia Tolstoyana, entonces, constituye el último momento en que D 'H almar intenta un proyecto de grupo. Fracasado éste, el epílogo de la primera etapa de D 'H al mar no será más quela pendiente quelo conducirá a la soledad y la errancia.

\section{DOS LECT URAS PARA UN MISM O ACONTECIMIENTO}

Para hablar de la Colonia Tolstoyana en relación con Augusto D 'H almar, es necesario plantear queel acontecimiento cultural que supuso, en el contexto de la escena del 900, admite dos lecturas necesarias de considerar. En primer lugar, está la leyenda que se tejió en torno a un proyecto que se consideró claramente contracultural y que dibujó el cuadro deal gunos artistas que decidieron retirarse de la ciudad y fundar una comunidad agrícola-artística animada por los principios del conde Tolstoy que tienen "por centro la fraternidad universal y la dicha en la unión". Los colonos, inspirados por un ideal que mezclaba elementos sociales y evangélicos, se animan a vivir una vida cercana a la tierra y al pueblo, en donde encontrarían el espacio necesario para el desarrollo de sus artes. Es necesario admitir que dicho proyecto entusiasmó a numerosos testigos que, desde Santiago, no dejaban de ponderar el impacto que tenía dicho intento, toda vez que, tanto en Chile como en Latinoamérica, surgían aires que movilizarían progresivamente agrupaciones de tipo social, obrero y artístico, en un clima de lenta pero decidida renovación.

Sin embargo, después de las M emorias de un tolstoyano, publicadas por Fernando Santiván en 1955, difícilmente se ha hecho sostenible esa primera lectura. Y no podía ser de otra manera, pues Santiván es, sin duda, el testigo privilegiado, el discípulo de primera hora, el que probablemente se entregó con más 
fervor al proyecto, el que más ha hablado sobre la Colonia y el que más pronto vivió la disconformidad.

\section{PROCESO DE CONFORMACION Y DISOLUCION DE LA COLONIA}

Cuando Santiván conoció a D 'H almar, éste gozaba de la fama del "héroe del momento" que "bajaba con lentitud (de la tarima del Ateneo), pero sin jactancia, despreocupado y elegante como un príncipequimérico, ofrecía el brazo a su viejecita y salía de la sala dignamente, saludando al pasar con fina sonrisa cordial" (Santiván, 1955: 93-94). En ese tiempo, los jóvenes estudiantes se agrupaban en torno a D 'H almar y lo saludaban con animados "vivas": " $\mathrm{iV}$ iva el Zola chileno!"... "iV ivanuestro D ostoiewsky!"... "iViva el Loti!"... "iviva el D audet!.." (Santiván, 1955: 94).

Santiván era un joven de 18 años que no podía ni deseaba abstraerse del influjo que ese escritor adolescente, apenas pocos años mayor, ejercía sobre él y sobre todos. La admiración que sentía por D 'H almar no puede ser mejor retratada que por él mismo: "Cuando penetré por primera vez en el santuario del escritor, temblaba como un adolescente católico al aproximarse ala Divina M esa" (Santiván, 1955: 95). La puerilidad del entusiasmo de Santiván por todo lo que D 'H almar representaba lo hizo decir en una ocasión, frentea varios contertulios que acudían a la casa del novelista: "-Tolstoy es como nuestro padre común... Yo... , yo... , iría en peregrinación hasta Rusia, sólo para besar sus manos venerables..." (Santiván, 1955: 97). Con el tiempo, reconocería que aquellos impulsos no eran sino un entusiasmo inocente que lo acercaría al "maestro" de forma incondicional y a Julio 0 rtiz deZárate, joven pintor, el único capaz de sentir los mismos afectos hacia D ' $\mathrm{H}$ almar y los complejos y nobles misterios que representaba.

Fue en una de las visitas que hacían al Parque Forestal para ritualizar la despedida del sol, cuando los tres comenzaron a hablar sobre "el tema deTolstoy, sobre la belleza de la vida sencilla, de la irresistencia al mal, del apostolado educativo que se podría ejercer entre los campesinos y de la necesidad de huir delos viciosos placeres de la vida ciudadana" (Santiván, 1955: 98).

Ese clima de ardoroso entusiasmo envolvió y obnubiló a Santiván. N o tenía aún los elementos para estructurar una mínima actitud de sospecha con respecto a los móviles de D 'H almar y las capacidades real es que todos ellos tenían para llevar a una feliz realización el proyecto en que se embarcaron. Serían necesarias las evidencias para que todo seviniera abajo y funcionara sólo por algunos meses.

Se puede afirmar queel punto de quiebre en la relación Santiván-D 'H almar surgió cuando viajaron hacia Arauco, con destino a las tierras que les tenían 
prometidas. Antes dellegar a ellas, Augusto D 'H almar' había desistido deir tan lejos y convenció a sus dos compañeros a regresar hasta San Bernardo en donde $M$ anuel M agallanes M oure podía ofrecerles un pequeño terreno:

A medida que nuestro compañero hablaba, yo sentía que una congoja aprisionaba mi garganta. Todos los sueños de silvestre libertad se venían por tierra. Todos mis proyectos de sacrificio, de lucha fiera contra los elementos de la naturaleza. ¡B osques, indios, temporales apocalípticos!... jSan Bernardo!.., jun arrabal de Santiago!... Para eso no valía la pena haber tirado por la borda nuestro porvenir..., estudios, pequeñas situaciones logradas, éxitos de otra índole... Sin embargo, ¿qué responder a nuestro amigo? La abuelita, la abuelita... (Santiván, 1955: 130).

Las palabras finales del párrafo citado representan un punto de la psicología d'halmariana que revela mucho de sus límitesfrente a sus proyectos. Carente de padrey demadre, todo su universo afectivo está organizado en torno a su "abue lita" de quien decía: "Es mi mejor escudo heráldico". La abuela apareceen todas sus presentaciones ante el Ateneo, ella es quien organiza la vida familiar para que el joven Thomson pueda dedicarse a escribir y organizar sus tertulias. La fijación y el apego que siente hacia ella le impiden separarla y separarse lo suficiente como para construir un proyecto independiente. En este caso, la abuelita (no ella, sino la dependencia de D 'H almar hacia ella) se constituye en un óbice para la realización dela Colonia en su radicalidad, convirtiéndola en un proyecto aguado y conciliador.

Se suman a esta "edípica" relación otros elementos de descontento para Santiván: el rechazo incomprensible que D 'H almar siente por las mujeres y el límite absoluto que impone al ingreso de ellas a la Colonia y al trato de los colonos con ellas, la comodidad que observa D ' $\mathrm{H}$ almar con respecto a los compromisos de mantención de la casa, el desdén con que D 'H almar desprecia la visita de los colonos obreros de la Colonia Tolstoyana de Pío N ono. En fin, numerosos aspectos que, a los ojos de Santiván, desacreditan la figura de D 'H almar y lo distancian progresivamente de él.

Probablemente, sea Fernando Alegría quien sintetiza mejor el cuadro de los tres miembros de la Colonia: "Santiván es el auténtico discípulo, D 'H almar el oficiante y O rtiz de Zárate el silencioso acólito" (Alegría, 1967: 59). Y quizás sea necesario, desde esta lectura, revisar completamentela historia de la Colonia Tolstoyana, quitándole a D 'H almar el lugar de protagonista que le ha asignado

\footnotetext{
1 “№ fue en gran parte la nostalgia de su hogar, el recuerdo de su abuela, lo que hizo disolverse en agua de lluvia esa intentona de colonizar los márgenes del lago al pie del volcán Villarrica? (D 'H almar, Recuerdos olvidados, p. 245).
} 
la leyenda para terminar afirmando que, si la misma logró subsistir algún tiempo, fuecasi exclusi vamente por los esfuerzos que real izó Fernando Santiván por realizar sus sueños. D e lo contrario, no se explica el pronto olvido y las pocas palabras de Augusto D 'H almar con respecto al proyecto. D e hecho, las únicas menciones suyas aparecen varias décadas después en su publicación Los 21 y en Recuerdos olvidados cuando, hablando de Tolstoy, dice:

D ebo recordar, no como anécdota personal, sino como dato histórico, que, hace exactamente cuarenta y cuatro años, se fundó en el sur de nuestro país una colonia dukoboer o tolstoyana, de escasa duración, es cierto, pero deimborrable memoria. Algunos de sus miembros, casi todos destacados después en sus actividades, por la vida, se han ocupado, bien en broma, bien en serio, de esa romántica y audaz tentativa. D e ella han solido contar anécdotas de oídas, quienes no tuvieron ocasión de compartirla; solamente yo, que la promoví, no he dicho sobre ella la última palabra y, si me apuran, ni siquiera he dicho media palabra. Acaso porque para mí haya cosas sagradas. Tal vez, quién sabe, porque los hombres que hemos tenido la suerte de entrar, así sea por un momento, en los dominios de la leyenda, no tenemos derecho de desvirtuarla. Recaiga, pues, el silencio, sobre la legendaria intentona tolstoyano-chilena del año 1904, y volvamos a Tolstoy, quien entonces vivía en Yasnaia-Poliana, y al darle nosotros parte de nuestras pretensiones, nos secundó con un giro postal por once rublos y una carta escrita con ininteligibles caracteres rusos. (Los 21, p. 44).

En síntesis, D 'H almar no discuteel lugar que a él lecupo en los hechos ni la veracidad de su liderazgo y protagonismo; prefiere dejar las cosas en el silencio de la leyenda, privándonos de una visión autocrítica, esperable -por ciertodespués de transcurridos tantos años.

Ahora bien, el liderazgo teórico de D 'H almar se desvanece al constituir él mismo, por sus preferencias, sus gustos y su forma de pujar para al canzar lo que realmente quería en sentidos divergentes y a veces contrarios, la principal fuerza entrópica del grupo. Es así que, tal parece, sólo 0 rtiz de Zárate y Santiván entendían verdaderamente la dimensión social del pensamiento de Tolstoy. Comparten, entre todos, ciertos pensamientos teóricos, pero se mantienen en permanentes discusiones respecto de la concreción práctica de sus proyectos en relación a la realidad chilena. Por lo visto, D 'H almar resistía el deseo de los jóvenes en el sentido de adquirir un compromiso práctico con la comunidad externa y plantear ciertas líneas de pensamiento que alimentaran la opinión nacional que - esto no es un dato menor- tenía sus ojos puestos en ellos y las propuestas renovadoras que surgieran del grupo.

Por otro lado, a los sentimientos fidelistas de Santiván y O rtiz de Zárate respecto de la doctrina de Tolstoy, se oponen los entusiasmos sincréticos de D 'H almar por los simbolistas, Poe, Verlaine, M allarmé, I bsen y M aeterlinck. Al 
respecto, afirma Fernando Alegría: “D 'H almar, rey de brumasy hechicero maestro en la preparación de filtros fantasmagóricos, construye en torno a sí mismo una cortina de humo que no es sino el equivalente de la torre de marfil del modernismo" (Alegría, 1967: 62). M ientras los jóvenes discípulos se proponen y luchan por vivir la coherencia de un proyecto desde el flanco de una férrea militancia, D 'H almar introduce fuerzas disgregadoras, incorpora subrepticiamente elementos que quizás él mismo no advierte como contradictorios, boga en las aguas peligrosas de un eclecticismo estético que socava las bases del ideario tolstoyano, flirtea vanidosamente con cada nuevo descubrimiento literario y parece ignorar que su personalismo lo está conduciendo aceleradamente a la radical separación respecto de sus pares, desu generación e, incluso, dela órbita intel ectual y artística chilena².

No tenemos los elementos para elaborar un juicio psicocrítico respecto del proceso d'halmariano, pero sí contamos con los acontecimientos y testimonios como para afirmar que, quizás a inicios de la Colonia Tolstoyana, fue la última vez que D 'H almar estuvo realmente acompañado y que fue, precisamente a partir de entonces, cuando aceleró su progresivo refugio en la soledad individualista que, poco más tarde, lo convertiría en el "hermano errante". D 'H almar, así, parecehaber vivido dos procesos simultáneos: el encantamiento por las brumas esotéricas y simbolistas y la pérdida de liderazgo con respecto a los escritores e intelectuales de su generación. Ambos procesos lo alejan del escenario de los primeros años del siglo XX (1900-1902, especialmente); ya no será más el joven aclamado por los estudiantes como el Zola o D ostoiewsky chileno, ya no subiráal Ateneo arrastrando la mirada complaciente de las multitudes, ya no estará a la cabeza de los machitunes, de las tertulias y de las columnas de arte que escribió en su primer período. En síntesis, D'H almar, coincidiendo con la progresiva disolución de la Colonia, va desapareciendo de la escena cultural como líder.

\footnotetext{
${ }^{2}$ D 'H almar, en la década de los '40, da una explicación a la soledad en que vivió desde la última etapa de su vida en Chile hasta su vejez. Dice que el hecho de no haber estado con su "abuelita" la noche en que ella murió, requería que la señal de que D ios lo podía perdonar era que "él mismo muriera abandonado y huérfano de afectos"... en efecto, dice más adelante: "H an pasado tantos años desdeentonces, 35, toda una existencia. El nieto, que peina canas y es a su vez un viejo, traza estos recuerdos y, en medio de ellos, al evocarlos, se desploma sobre sus cadáveres, como aquella noche del comedor y del jardín, y las lágrimas lo ciegan. ¿Tiene a alguien junto a sí, para rozar sus cabellos? Si está solterón, si mueresolo, es señal de que Dios ha querido perdonarlo" (Recuerdos olvidados, pp. 254, 255-256).

Esta explicación religiosa a su soledad no rinde cuentas del hecho que quiero demostrar y que es que las verdaderas razones dela misma están másfundadas en las opciones de alejamiento queél mismo tomó, producidas por sus necesidades personales y psicológicas, por su permanente errancia, y - por qué no decirlo- por las tendencias de una sexualidad que no parecían ofrecerle más alternativas que la distancia.
} 
H ay que pensar, sin embargo y como contraparte, que, a pesar del presumible dolor que pudo significar para D 'H almar esta pérdida de protagonismo (además de los conflictos explícitos con Santiván y la muerte de su "abuelita"), esta gestación de una nueva individualidad le permiten ganar autonomía respecto de las expectativas de los demás. Pierde el líder cultural, pero gana el escritor. Si no se hubiera dado este "cambio de piel", quizás no contaríamos con las obras que surgen después de este período: La lámpara en el molino, Gatita, La sombra del humo en el espejo, N irvana, Pasión y muerte del cura D eusto. Un D 'H almar liberado de las contiendas criollistas y naturalistas de las dos primeras décadas se permite "soñar" por anticipado. En beneficio suyo, es necesario reconocer que ese impulso de independencia tiene origen en un espíritu avizor capaz de captar el rumor estético del futuro, adelantándose siempre con respecto a los suyos, haciéndose extraño a ellos y buscando ingenuamente el acomodo a sus visiones, no captando que aún no está el terreno preparado para ellas. Considérese solamente lo que supuso la lectura de La lámpara en el molino (escrita antes de terminar 1907 y publicada en 1915). Es poco comprensible para sus admiradores de antaño que un tolstoyano como el que esperaban que fuera D 'H almar (y que nunca fue) escribiera tantas páginas desencarnadas que el maestro de Yasnaia Poliana jamás habría patrocinado.

Lo cierto es que el proceso de disolución de la Colonia Tolstoyana acabó siguiendo la ley natural: primero volvieron a Santiago los que "habían ido como turistas de guardapolvo y con la paleta de colores en la mano. D espués los más fervorosos. Y, por último, los recal citrantes: Santiván y D 'H almar" (Alegría, 1967: 66). La estadía de los dos en San Bernardo, sin embargo, atiende a otras razones. Santiván se enamora de la hermana de D 'H almar y se casa con ella, cuestión quetermina por destruir la relación entre ambos. Celosterribles, sentimiento de posesión respecto de su hermana (y quizás respecto del mismo Santiván) impiden que D ' $\mathrm{H}$ almar mire con buenos ojos tal matrimonio. La determinación que tomó no fue la aceptación, sino el alejamiento. La triangularidad de esta relación no dejó de aparecer posteriormente en su narrativa. Así, por ejemplo, poco menos de veinte años después, aparecería la novela de un joven sacerdote que sealeja desu diócesisy región a causa de queun muy querido ex compañero de seminario se había casado con su hermana.

\section{LA COLONIA TOLSTOYANA Y LA CRITICA}

El acontecimiento "Colonia Tolstoyana" mereció la mención de algunos escritores y críticos: En un primer momento lo hizo M ariano Latorre (el más confiado y menos escéptico con respecto a los móviles de D 'H almar); en 1958, Julio 
O rlandi; en 1962, Fernando Alegría y Alone. Q uizás sea O rlandi el primero que menciona algo del carácter de D 'H almar y su efecto en la comunidad:

Algunos intentos previos de fijarla en la región de Arauco fracasaron por el clima y el enfermizo apego de D 'H almar a su abuelita. Pobreza, orden, aseo y sobre todo sumisión incondicional al jefe, parecían ser las normas imperantes. Era D 'H almar un espíritu absorbente que no admitía objeciones a sus dictámenes (O rlandi, 1959: 11).

Un punto que no se menciona (ni siquiera el mismo Santiván lo hace) es el de la homosexualidad de D 'H almar. No lo hace Santiván, ni para hablar de Augusto D 'H almar, en forma independiente, ni para hacerlo con respecto a sus relaciones con los miembros de la Colonia. Tal parece que Santiván no cree haber pensado ( 0 al menos haberse atrevido a manifestar) que la tendencia homoerótica de D ' $\mathrm{H}$ almar estuviera detrás de sus comportamientos extraños. Es Alone el que, en 1962, menciona el tema explícitamente:

... hay algo que Santiván no dice, que hasta ahora nadie ha dicho claramente, aunque todos lo saben: el uranismo de D'H almar, que no lo explica todo, pero sin lo cual nada se entiende.

Creemos llegada la hora de no hacerse más desentendido de ese, por lo demás, secreto a voces (Alone, 1962: 19).

Alone se atreve a inferir que, tras este uranismo, está la respuesta a los conflictos al interior del grupo:

D'H almar, cuyos gustos eran definidos e intransigentes, no podía soportar a las mujeres y las excluyó de la Colonia. Sobre eso cuenta Santiván anécdotas que no dejan duda. Basta leerlo un poco al trasluz y poner la clave. Así se aclara aquel simbólico desaire inferido por el señor de la Colonia a las curiosas vecinas intrigadas por los tres mozos cuando se asomaron a la ventana para verlos (Alone, 1962: 19).

M ás adelante, refutando la lectura acrítica de M ariano L atorre, sospecha de las motivaciones social es (en seguimiento a Tolstoy) que propiciara D ' $\mathrm{H}$ almar y que defendiera Latorre:

No tenemos para qué averiguar si el joven tolstoyano, autor de las memorias, se dio o no se dio cuenta de los fines que la expedición colonial tenía ni delas razones de su fracaso, con aquel regreso tan desalentado de los tres; pero un simple examen de los hechos y la psicología del que los orientaba permite 
sonreír ante las complicadas lucubraciones que el suceso ha originado. "Aventura única en Sudamérica" la llama Latorre, quien atribuye a Thomson un incansable proselitismo, una gran fe "en el valor humano de su arte y de sus compañeros". El mismo escritor anota la interesante circunstancia de que entreTolstoy, el apóstol, y G orki, el político, fuese aquél y no éste quien prevaleciera en el espíritu del joven, sacando la consecuencia de que "T homson quería, no cabe duda, despertar la responsabilidad del escritor en la lucha social desu país de origen y hermanarlo con los políticos, con los maestros, con los hombres deacción, en suma". O bservaciones muy sagaces, pero que no llevan bue na dirección. Porqueel espíritu proselitista de D ' $\mathrm{H}$ almar, entonces Thomson, no puede discutirse, está a la vista; pero que quisiera "despertar la responsabilidad de los escritores en la lucha social" ya es otra cosa, tan distinta como el continente del contenido y la fachada del interior. Un gran impulso de amor movía la empresa de los tres soñadores, y a los sueños de cada uno se mezclaban seguramente la ilusión apostólica, el embrujo literario, la necesidad de sacrificio propia de la juventud y muchos otros elementos nobles; pero, por dentro, dos de ellos obedecían al maestro, al jefe, al organizador y sumo sacerdote de la cofradía expedicionaria, sin saber que a éste lo arrastraba, con la fatalidad de los sentimientos condenados e irresistibles, "el amor que no osa decir su nombre", la desviación erótica que llevó a la cárcel a W ilde y hace tan tristes las errancias marineras de Loti (Alone, 1962: 19-20).

A mí parecer, el aporte de Alone respecto a sacar a la luz la realidad homoerótica de Agusto D 'H almar es señero, sobre todo porque instala una clave que no puede ser desconocida por los estudios posteriores: "el uranismo de D 'H almar (...) no lo explica todo, pero sin el cual nada seentiende". También es sugerente la crítica que formula a la visión de M ariano Latorre respecto del ideario social que los animaba, criticando así el cuerpo del discurso contenido por la leyenda en torno a la ColoniaTolstoyana. Lo quesí me parece desapropiado es que ponga a la base de las motivaciones d'hal marianas sus particulares inclinaciones sexuales, confinándolas a la condena, a una especie de determinada e irresistibleinclinación por arrastrar a los demás hacia el rumbo dela fatalidad de sus deseos secretos. No me parece justo descomplejizar las cosas a este nivel, menos aún cuando no se cuenta con ningún argumento o testimonio que indique positivamente que D ' $\mathrm{H}$ almar hubiera actuado en al gún momento con una clara intención erótica privatizante respecto de 0 rtiz de Zárate o Santiván. Es lógico suponer que, en el fondo subconsciente de la naturaleza de sus actos, muchos elementos se mezclaran sin dar clara cuenta de dónde empezaban unos y dónde terminaban otros; pero, hacer radicar todo en una inclinación homosexual puede ser insuficientemente argumentable e injusto con respecto a los móviles artísticos que impulsaban al joven Thomson. Prefiero seguir creyendo que el carácter de D 'H almar era caprichoso, absorbente, contradictorio y varia- 
ble; tal vez, a la raíz, había múltiples factores psicológicos que no podemos escrutar en su totalidad, entre los cuales se cuenta su homosexualidad. Sin embargo, es más posible pensar que natural ezas como la suya, dotadas de una inteligencia poco común, eran capaces de contener los impulsos de una sexualidad que, por aquel entonces, no "osaba decir su nombre" y mantenerlos en el cuarto fondo, sobre todo si se piensa en el contexto social de principios de siglo, claramente represivo frente al tema. Creo, además, que recién después de iniciados sus viajes, D 'H almar se atrevió a tomar alguna postura práctica con respecto a su homosexualidad. D e hecho, el que regresó en 1934 era distinto: un joven médico lo acompañaba (su pareja, dicen muchos) y había escrito varias novelas dondeel homoerotismo empezó a figurar en el discurso de la narrativa hispanoamericana; no en vano, al gunos lo consideran como el fundador de la narrativa homoerótica en $\mathrm{H}$ ispanoamérica. Q uizás a Alone le faltó comprender que el proceso de la vivencia de la homosexualidad, en contextos claramente represivos, pasa primero por una larga fase de silenciamiento o sublimación (permaneciendo la mayoría en esta fase) y que sólo se manifiesta como realización después de que muchos resortes se han roto y algunas condiciones se dan. Es muy poco probablequeel joven Thomson, tan deseoso de agradar a las multitudes, a su abuelita, a sus hermanas, y tan cobarde como para manifestar alguna señal de algo que, en ese momento, habría sido considerado un grave defecto, hubiera vivido sus deseos en algún grado antes de despedirse de Chile. Es claro, también, que en la lectura de Alone figuran elementos ex post, datos incorporados recién después de su regreso (1934) y que, leídos en forma simplista y aplicados acríticamente a eventos ocurridos más de 27 años antes, invalidan una lectura justa de los acontecimientos relacionados con la Colonia Tolstoyana.

\section{DOS TENDENCIASEN PUGNA}

Es posible afirmar queel cuadro representado por los tres miembros principales de la Colonia Tolstoyana señala sintéticamente los elementos que describen el corazón delas pugnas y polémicas dela época. Cuando Santiván diceque "nuestro compañero ( $\mathrm{D}$ 'H almar) era, ante todo, artista y nada más que artista" y que "Tolstoy había penetrado en su espíritu" no por "teorías morales sino por el camino encantado del arte" (1955), está exponiendo dos posibilidades de seguimiento del inspirador de la Colonia: una queva por la vía del artey otra por la vía de la creación de un proyecto social. La leyenda generada por este proyecto de corta duración tuvo importancia -en palabras de H elena Tzitsikas (1971: 14)- por cuanto "expresó el deseo de idealidad de la juventud artística y creado- 
ra de la época". Sin embargo, el peso de esa idealidad asignaba a la literatura y al arte una función claramente social, camino del que D 'H almar ciertamente se separa.

U no de los pocos párrafos de $\mathrm{D}$ 'H almar dedicados a hablar de la vida cotidiana en la Colonia denuncia implícitamente la contradicción que ella misma vivía:

A ciertas horas de descanso, dedicadas a hacer tertulia entre ellos, todos se reunían en la Kashbah (como con poca propiedad de lenguaje y ninguna del edificio, Ilamaban a la casa) y, según ya apuntamos, su programa monótono y que, sin embargo, no llegaba nunca a cansarles, era tomar téo mate y hablar de Loti (Recuerdos olvidados, p. 248).

La participación de Loti en ese escenario revela una influencia d'halmariana clara y constante, el cual no tuvo dificultades para introducir -como ya se decía- éste y muchos otros elementos entrópicos en la configuración y real ización de un proyecto más sólido y coherente.

Sin embargo, el mismo D 'H al mar que estimuló a leer a Loti es el que admiraba a Tolstoy. $V$ ista, entonces, con la perspectiva de la distancia, la coexistencia de estas preferencias dispares, hacen de él un líder generacional, cuyo influjo contribuye a la gestación de las dos grandes tendencias de la época. Así, en palabras de D ieter 0 elker,

... resulta interesante constatar que participó con su obra ( $D$ 'H almar) en la gestación de los dos movimientos literarios antagónicos que se iniciaron en el período: uno cosmopolita, imaginativo y autotélico, y otro criollista, realista y comprometido (0 elker, 1995: 187-188).

La visión comprensiva del período 1900-1907 permite ver a D 'H al mar participando de ambas corrientes y, en cierto modo, inaugurándolas.

En la misma línea, G eorge E. Smith sintetiza el cuadro de la G eneración de 1900, de la cual D 'H almar se siente parte, del siguiente modo:

We see, then, three definitive sub-trends in the G eneration of 1900. A leaning of some writers toward the campo on the one hand is balanced by those who find their muse in the lowest districts of the large metropolis. Both of these groups are inspired by the land, however. A third group refuses terrestrial or geographic bounds and sees within each individual a new, unexplored, international territory offering a multi-faceted source of inspiration (Smith, 1969: 554).

Es así cómo aparecela polémica entre la tendencia criollista (orientada hacia el campo y la ciudad) y la tendencia denominada imaginista. El cosmopolitis- 
mo de D 'H almar supera sus tentativas "criollistas" iniciales, pero será él, sin duda, la síntesis de esa misma pugna, el encuentro del "cosmopolitismo" y del "color local", cuestión que lo hace constituir - por sí mismo- un fenómeno interesante de estudiar. Y es con esa, su doble naturaleza, su incapacidad de renunciar a una u otra preocupación artística, quellega a la ColoniaTolstoyana, infiltrando en ella el germen de una cierta esquizofrenia proyectual eimpidiéndole realizarse y exten derse como la gran comunidad social que todos quisieron ver durante décadas.

\section{CONCLUSION : EL VALOR DE UNA EXPERIENCIA UNICA}

1. La Colonia Tolstoyana de San Bernardo vale como una experiencia señera que recoge un pequeño núcleo de la G eneración de 1900 y que representa los intereses deuna época en que aún no era posible discernir el valor de losinflujos artísticos procedentes especialmente de Europa. D ichas influencias ingresan a nuestra incipiente formación cultural generando tendencias, agrupando intereses, verificando posturas. $\mathrm{H}$ ijos de esta generación, losfuturos criollistas eimagi nistas deberían sentirse deudores, puesfue precisamente, desde la experiencia de estos primeros artistas, que comenzó a gestarse esta doble orientación de las artes hacia la "naturaleza" o el "espíritu", hacia la "mimesis" o la "poiesis", principios centrales en la determinación de las distintas escuelas que dominaron la escena cultural chilena del 900.

2. D 'H almar, el pontífice de esa pequeña comunidad, fue al mismo tiempo el fundador y el destructor de la misma. La fundó en virtud de su capacidad para congregar en torno a sí algunos jóvenes decididos a dejarlo todo por un proyecto; la destruyó en la medida que no supo ver que las instituciones no funcionan sólo sobre la base de una inspiración carismática, sino que necesitan un ordo, una "regula" estable que centre los esfuerzos en función de un proyecto y una línea conductora en la cual todos han de sacrificar al go. Y lo quea él le faltó por sacrificar fue su afán sincrético por acogerlo todo con igual interés y novedad, ignorando que las brumas melancólicas de muchos de sus autores preferidos no ayudaban a sus intereses iniciales en Tolstoy.

3. La experiencia de Augusto D'H almar en la Colonia Tolstoyana terminó en definitiva soledad para él. Poco después vendría la muerte de su abuelita, el matrimonio de su hermana, la ruptura con Santiván, los viajes. D e ese proceso, finalmente, emergería el escritor que venía en gestación, en sacrificio del líder cultural que no pocas empresas motivara a inicios de 1900. U na segunda etapa 
fecunda en escritos procede a la crisis tolstoyana. Lo demás quedaría en "leyenda".

4. Las dos colonias tolstoyanas (la de Pío N ono y la de San Bernardo) tuvieron existencias casi paralelas. Terminaron por razones distintas: la primera por persecuciones políticas y falta de recursos; la segunda, por las razones vistas. A mbas supusieron la existencia de una vitalidad juvenil que quería responder, desde distintosflancos, a un ideario social que el tiempo se ha encargado de desmitificar, coexistiendo lecturas que las sitúan en la leyenda o, alternativamente, las instalan en la sospecha del más variado tipo. Sin embargo, no se puede desconocer que este gesto, esta aventura, levantó una propuesta surgida de los nuevos vientos que comenzaron a soplar con el cambio de siglo y que significaron múltiples alcances en las décadas posteriores. ¿Q uién podría desconocer en estos desventurados tolstoyanos una suerte de paternidad respecto de los arriesgados vanguardistas de la década de los veinte? Es justo reconocer quea todo proyecto le acompañen siempre las limitaciones humanas; pero no lo es atribuir a esas limitaciones la única razón de su existencia. En este sentido, quizás el párrafo final dedicado por Fernando Alegría a "Ios tolstoyanos" me parezca el más equilibrado de todos, pues, sin ingenuidad, es capaz de reconocer la riqueza de su aporte a la vida cultural chilena:

La sombra del patriarca de Yasnaia Poliana se extendió sobre ellos, artistas, escritores, obreros, y dejó sobre sus hombros el peso invisible y cálido de una mano guiadora. La vida les iba a apartar y a confundir en una época de violencias y angustias. Algunos partieron a vagar por el mundo inventándose, como D'H almar, un barco y una tierra prometida; otros afrontaron la contienda en tierra criolla y, desde la tribuna, desde la literatura, desde la política, libraron memorables combates. Sobre ellos y sobre otra generación que recibió con unción el mensaje y salió, a su vez, a difundirlo -la generación de 1920, la de Claridad-, la sombra deTolstoy no cesó de regalar ternura, bondad, devoción, y amor a la justicia, amor a la tierra y al pueblo que de ella vive (Alegría, 1967: 66).

\section{REFERENCIAS}

Alone (H ernán Díaz Arrieta). 1962. L os cuatro grandes de la literatura chilena durante el siglo XX: Augusto D'H almar, Pedro Prado, Gabriela M istral, Pablo N eruda. Santiago, C hile: Ed. Zig-Zag. 234 pp.

Alegría, Fernando. 1967. "Tolstoyanos chilenos" en: Literatura chilena del siglo XX. Santiago, Chile: Ed. Zig-Zag. Pp. 171-190. 
Arriagada, Julio y G olsack, H ugo. 1952. Augusto D'H almar (2 tomos). Santiago, Chile: M inisterio de Educación Pública, Colección Ensayos Literarios.

Bourgois, Louis C. 1963. "TheTolstoy Colony, a chilean utopic artistic experiment", en H ispania XLVI, 3, pp. 514-518.

D 'H almar, Augusto. 1969 (1948). "Tolstoy, el ultimo profeta", en: Los 21. Santiago, Chile: Ed. N ascimento. Pp. 41-52.

-... 1975. Recuerdos olvidados. Santiago, Chile: Ed. N ascimento.

D ela Vega, D aniel. 1923. "U na colonia tolstoyana”, en: LasU Itimas N oticias. Santiago, Chile, 19 de noviembre.

Espinosa, Januario. 1928. "La ColoniaTolstoyana”, en: Atenea V, 2, pp. 166-169.

--------. 1933. "Augusto D'H almar y la C olonia Tolstoyana", en: Atenea XXV, 103, pp. 155-170.

0 elker, D ieter. 1995. "La Colonia Tolstoyana”, en Atenea 471, Concepción, pp. 177190.

O rlando, Julio y Ramírez, Alejandro. 1959. Augusto D'H almar: O bras, estilo, técnica. Santiago, Chile: Ed. Pacífico, 64 p.

Santiván, Fernando. 1955. M emorias de un tolstoyano. Santiago, Chile: Zig-Zag. 354 pp.

Smith, George E. 1969. "T he Chilean Literary Scene: 1900", en: H ispania XLIII, 4, pp. 552-558.

Tzitsikas, H elena. 1971. Fernando Santiván. H umanista y literato. Santiago, Chile: Ed. N ascimento. 